\title{
RESPOSTA DE MUDAS DE GOIABEIRA À APLICAÇÃO DE ZINCO ${ }^{1}$
}

\author{
WILLIAM NATALE ${ }^{2}$, RENATO DE MELLO PRADO $^{3}$, MÁRCIO CLEBER DE MEDEIROS CORRÊA $^{3}$, MARCOS ANTONIO \\ CAMACHO DA SILVA ${ }^{4}$, LUCIANO PEREIRA ${ }^{5}$
}

\begin{abstract}
RESUMO - O subsolo, normalmente utilizado para produção de mudas de frutíferas, apresenta baixa concentração de zinco e, assim, existe grande probabilidade de resposta à aplicação deste micronutriente. Considerando a falta de informações sobre o assunto, procurou-se avaliar o efeito da aplicação de zinco ao substrato de produção das mudas de goiabeira e acompanhar os efeitos no desenvolvimento, na produção de matéria seca e no estado nutricional das plantas. O delineamento experimental foi em blocos ao acaso, com cinco tratamentos e cinco repetições. As doses de zinco, na forma de sulfato de zinco, foram: 0; 2; 4; 6 e $8 \mathrm{mg} \mathrm{dm}^{-3} \mathrm{de} \mathrm{Zn}$. No plantio, as mudas receberam doses de N, P, K e B de 300; $100 ; 150$ e 0,5 mg dm ${ }^{-3}$, respectivamente. O experimento foi conduzido em viveiro telado, em vasos com 2,8 dm $\mathrm{dm}^{3}$ de substrato de um Argissolo Vermelho-Amarelo. Após 135 dias do plantio, avaliaram-se: a altura, a área foliar e a matéria seca da parte aérea e das raízes, bem como os teores de macronutrientes e de Zn. As mudas de goiabeira responderam positivamente à aplicação de zinco. O maior desenvolvimento das mudas esteve associado à dose de $2 \mathrm{mg} \mathrm{dm}^{-3} \mathrm{de} \mathrm{Zn}$. Doses iguais ou superiores a $4 \mathrm{mg} \mathrm{dm}^{-3}$ causaram redução significativa no desenvolvimento e no acúmulo de macronutrientes nas mudas de goiabeira.
\end{abstract}

Termos para indexação: $\mathrm{Zn}$, goiaba, Psidium guajava.

\section{RESPONSE OF GUAVA TO ZINC APPLICATION}

ABSTRACT - The subsoil normally used for guava cuttings production presents low concentration of Zn. Considering the inexistence of information on the subject, it was studied to evaluate the effect of zinc application in the substratum of production of the guava cuttings and, to follow the effect in the development, the production of dry matter and the nutrition status of plants. The experimental design used was randomized blocks with 5 treatments and 5 replications. The doses of zinc were: $0 ; 2 ; 4 ; 6$ and $8 \mathrm{mg} \mathrm{dm}^{-3}$ of $\mathrm{Zn}$. All plants received constant doses of N, P, K and B of 300; $100 ; 150$ and $0.5 \mathrm{mg} \mathrm{dm}^{-3}$ of $\mathrm{Zn}$ respectively. The experiment was lead in vases with $2.8 \mathrm{dm}^{3}$ of substratum of a Yellow Red Argissolo (Ultisol). After 135 days of planting, it was evaluated: height, foliar area, dry matter, nutritional status of plants and soil nutrients. The guava had answered positively to zinc application. The biggest development of the plants was associated with $2 \mathrm{mg} \mathrm{dm}^{-3}$ of $\mathrm{Zn}$ dose. The equal or upper doses $4 \mathrm{mg} \mathrm{dm}^{-3}$ of $\mathrm{Zn} \mathrm{had}$ presented significant reduction in the growth and the accumulation of macronutrients in the guava cuttings.

Index terms: Zn, guava, Psidium guajava.

\section{INTRODUÇÃO}

Estudos da FAO (1998) indicam que a demanda por frutas no mundo vem crescendo a exemplo do mercado consumidor de frutas tropicais, que está em franca expansão, atingindo crescimento anual da ordem de 3 a $6 \%$.

O Brasil é o maior produtor mundial de frutas in natura. Entretanto, apesar deste destaque, ocupa o $12^{\circ}$ lugar nas exportações (Fachinelo et al., 1996). Existe, pois, um grande potencial para o crescimento das exportações de frutas. Porém, a metade de todo o volume produzido concentra-se num só produto: a laranja. Desta forma, a diversificação de frutíferas torna-se importante. Dentre as opções indicadas de fruteiras aptas para serem cultivadas no estado de São Paulo, apresentando boas perspectivas, estaria a goiabeira.

$\mathrm{Na}$ implantação de um pomar, a qualidade das mudas torna-se fundamental para garantir a homogeneidade, uma rápida formação e um início precoce de produção. Para obter mudas de boa qualidade, o estado nutricional da planta é de extrema importância, visto que os viveiristas utilizam o subsolo (camada de $0-4 \mathrm{~m}$ ), ácido, e de baixa fertilidade para compor o substrato, atendendo às exigências do Ministério da Agricultura para produção de mudas certificadas (Brasil, 1977), as quais devem estar livres de ervas daninhas e patógenos. Por outro lado, é conhecido que os solos tropicais, devido ao intemperismo, apresentam baixo teor de micronutrientes, especialmente de zinco.

Assim, para a produção de mudas de forma eficiente, o uso agronômico de zinco pode favorecer a obtenção de plantas com qualidade e estado nutricional adequado. Como a quantidade de $\mathrm{Zn}$ aplicada por muda é muito pequena, tem-se alta relação benefício/custo, com maior sustentabilidade nos sistemas de produção. Algumas indicações do benefício do $\mathrm{Zn}$ no crescimento e redução de doenças foliares em goiabeiras adultas são encontradas em Vasudeva \& Raychaudhuri ( 1954) e Prasad et al. (1966).
O zinco é um elemento essencial, podendo afetar o crescimento e o metabolismo normal de espécies vegetais, quando o ambiente apresenta níveis tóxicos ou insuficientes (Marschner, 1995). As plantas apresentam concentrações tóxicas de Zn distintas em função da espécie, sendo a faixa de 100 a $400 \mathrm{mg} \mathrm{kg}^{-1}$ considerada tóxica para o crescimento da maioria das plantas (Kabata-Pendias \& Pendias, 1985). Entretanto, existem espécies mais tolerantes à toxidez de $\mathrm{Zn}$, como o eucalipto, variando de 698 a $853 \mathrm{mg} \mathrm{dm}^{-3}$ de $\mathrm{Zn}$ (Soares et al., 2001).

Considerando a falta de informações sobre o assunto, procurou-se avaliar o efeito da aplicação de zinco no substrato de produção das mudas de goiabeira e acompanhar os efeitos no desenvolvimento, no estado nutricional e na produção de matéria seca das plantas.

\section{MATERIAL E MÉTODOS}

O estudo foi desenvolvido em um viveiro comercial de mu-

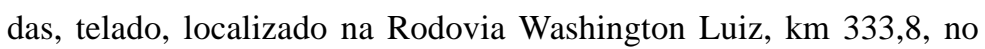
município de Taquaritinga-SP. Como substrato, utilizou-se o subsolo de um Argissolo Vermelho-Amarelo (camada 30-300 cm). Realizaramse análises químicas do substrato, antes da calagem e após 30 dias de incubação, por ocasião do plantio (Tabela 1).

TABELA 1- Propriedades químicas do substrato ${ }^{(*)}$ de um Argissolo VermelhoAmarelo, utilizado na produção de mudas de goiabeira

\begin{tabular}{|c|c|c|c|c|c|c|c|c|c|c|}
\hline $\begin{array}{c}\mathrm{pH} \\
\left(\mathrm{CaCl}_{2}\right) \\
\end{array}$ & M.O. & $\begin{array}{c}\mathrm{P} \\
\text { (resina) }\end{array}$ & K & $\mathrm{Ca}$ & $\mathrm{Mg}$ & $(\mathrm{H}+\mathrm{Al})$ & SB & $\mathrm{T}$ & V & $\mathrm{Zn}$ \\
\hline & $\mathrm{g} \mathrm{dm}^{-3}$ & $\mathrm{mg} \mathrm{dm} \mathrm{m}^{-3}$ & & & $\overline{\text { Ant }}$ & $\mathrm{mmol}_{\mathrm{c}} \mathrm{dm}$ & & & $\%$ & $\mathrm{mg} \mathrm{dm}{ }^{3}$ \\
\hline 4,3 & 6 & 1 & 0,7 & ${ }^{6}$ & $\begin{array}{c}3 \\
\text { ós a }\end{array}$ & $\begin{array}{c}25 \\
\text { alagem ( }\end{array}$ & $\begin{array}{c}9,7 \\
\text { antio) }\end{array}$ & 34,7 & 28 & 0,2 \\
\hline 6.0 & 6 & 2 & 0.8 & 22 & 10 & 16 & 32.8 & 48.8 & 67 & 0.1 \\
\hline
\end{tabular}

(*) O substrato é resultado da mistura da camada de $30-300 \mathrm{~cm}$ do perfil do Argissolo Vermelho-Amarelo, utilizado na produção das mudas.

1 (Trabalho 005/2002). Recebido: 17/01/2002. Aceito para publicação: 06/06/2002.

2 Professor Adjunto, Departamento de Solos e Adubos, FCAV/Unesp, campus Jaboticabal. Via de Acesso Prof. Paulo Donato Castellane, s/n., 14870-000, Jaboticabal-

SP. E-mail: natale@fcav.unesp.br Bolsista do CNPq

3 Doutorando, Departamento de Solos e Adubos, FCAV/Unesp, campus Jaboticabal, E-mail: rmprado@ @ fav.unesp.br. Bolsista FAPESP.

4 Mestrando, Departamento de Solos e Adubos, FCAV/Unesp, campus Jaboticabal,. Bolsista FAPESP.

5 Graduando do Curso de Agronomia, FCAV/Unesp, campus Jaboticabal. 
Utilizaram-se vasos com $2,8 \mathrm{dm}^{3}$ de substrato, os quais receberam mudas de goiabeira (Psidium guajava L.) cv. Paluma, propagadas vegetativamente a partir de estacas herbáceas.

Tendo em vista as condições de acidez do substrato, realizouse a calagem, objetivando elevar a saturação por bases a 70\%, indicada como ideal para a goiabeira (Santos \& Quaggio, 1996). Para isto, foi utilizado o calcário calcinado tipo $\mathrm{D}$, com as seguintes características: $\mathrm{CaO}=420 \mathrm{~g} \mathrm{~kg}^{-1} ; \mathrm{MgO}=250 \mathrm{~g} \mathrm{~kg}^{-1} ; \mathrm{PN}=137 \% ; \mathrm{RE}=96 \%$ e PRNT $=131 \%$. A dose de calcário calculada, $1,12 \mathrm{t} \mathrm{ha}^{-1}$ ou $1,6 \mathrm{~g}$ por vaso de $2,8 \mathrm{dm}^{3}$, foi homogeneamente aplicada ao substrato 30 dias antes do transplante das mudas e da aplicação dos tratamentos, para que o corretivo tivesse tempo suficiente para a neutralização da acidez do solo.

$\mathrm{O}$ delineamento experimental adotado foi em blocos casualizados, com cinco tratamentos e cinco repetições. Os tratamentos foram doses crescentes de zinco, na forma de sulfato de zinco $(22 \%$ de $\mathrm{Zn}$ ), considerando-se como parâmetro a dose média de $5 \mathrm{mg} \mathrm{dm}^{-3} \mathrm{de}$ $\mathrm{Zn}$, indicada como adequada para experimentos em condições de vasos, segundo recomendação geral de Malavolta (1981). As doses foram calculadas como segue: $\mathrm{D}_{0}=$ zero de $\mathrm{Zn} ; \mathrm{D}_{1}=2 ; \mathrm{D}_{2}=4 ; \mathrm{D}_{3}=6 ; \mathrm{D}_{4}=8 \mathrm{mg}$ $\mathrm{dm}^{-3}$ de Zn. Estas doses corresponderam a: 0; 27,3; 54,5; 81,8 e 109,1 $\mathrm{mg}$ de sulfato de zinco por vaso, respectivamente.

Ainda por ocasião do plantio, cada unidade experimental recebeu doses de nivelamento para $\mathrm{P}\left(100 \mathrm{mg} \mathrm{dm}^{-3}\right)$ conforme indicação de Kanegae (1998), N (300 mg dm$\left.{ }^{-3}\right), \mathrm{K}\left(150 \mathrm{mg} \mathrm{dm}^{-3}\right)$ e B $\left(0,5 \mathrm{mg} \mathrm{dm}^{-3}\right)$, de acordo com a recomendação de Malavolta (1981), na forma de superfosfato triplo ( $41 \%$ de $\mathrm{P}_{2} \mathrm{O}_{5}$ ), sulfato de amônio $(20 \%$ de $\mathrm{N}$ ), cloreto de potássio $\left(60 \%\right.$ de $\left.\mathrm{K}_{2} \mathrm{O}\right)$ e ácido bórico (17\% de $\left.\mathrm{B}\right)$, respectivamente. $\mathrm{O} \mathrm{N}$ e o $\mathrm{K}$ foram parcelados em quatro aplicações: no plantio e após 30, 45 e 60 dias. Os adubos $\mathrm{P}$ e $\mathrm{B}$ foram adicionados em dose total por ocasião do plantio.

A irrigação foi mantida continuamente durante a condução do experimento, tomando como base a umidade correspondente a $70 \%$ da capacidade de campo do solo.

Aos 135 dias após o plantio, foram avaliados os parâmetros biológicos indicativos do desenvolvimento das plantas, como: altura, índice de área foliar, matéria seca da parte aérea e das raízes das plantas. Na mesma ocasião, o estado nutricional das plantas foi avaliado, dividindo-se as mudas em parte aérea e raízes. As determinações dos teores de macronutrientes e do zinco no tecido vegetal seguiram a metodologia de Bataglia et al. (1983). Amostragens de solo foram realizadas na mesma época, e as determinações analíticas seguiram as recomendações de Raij et al. (2001).

Com base nos resultados obtidos, realizaram-se análises de variância para os diversos parâmetros estudados e análise de correlação entre os tratamentos, e as determinações no solo e na planta.

\section{RESULTADOS E DISCUSSÃO}

\section{Efeito dos tratamentos no solo}

A aplicação do calcário ao substrato promoveu a adequada neutralização da acidez do solo, elevando a saturação por bases a $67 \%$, bem próxima do calculado $(70 \%)$ e, ainda, como esperado, reduziu a disponibilidade do zinco, ou seja, de $0,2 \mathrm{mg} \mathrm{dm}^{-3} \mathrm{de} \mathrm{Zn}$ antes da calagem, para $0,1 \mathrm{mg}$ após a calagem; entretanto, ambos os valores para solos são considerados baixos $\left(<0,7 \mathrm{mg} \mathrm{dm}^{-3}\right)$, segundo Raij et al. (1996).

Conforme se esperava, houve incremento linear da concentração de zinco no substrato em função da sua aplicação no Argissolo Vermelho-Amarelo (Figura 1). Pelos resultados, observa-se que o aumento foi de 0,2 (na dose zero) para 3,7 $\mathrm{mg}$ (na dose de $8 \mathrm{mg} \mathrm{dm}^{-3}$ ). Assim, obteve-se uma excelente correlação $\left(\mathrm{R}^{2}=0,99^{* *}\right)$ entre as doses de zinco aplicado e o $\mathrm{Zn}$ determinado no solo, indicando a adequabilidade do DTPA na extração do micronutriente.

A recuperação do zinco foi de $47 \%$, valor esse superior ao obtido por Barman et al. (1998), que foi de até 31\%, usando o mesmo extrator. Esta diferença se deve, possivelmente, ao uso de solos distin- tos. Salienta-se, ainda, que, segundo Raij et al. (1996), os teores baixo, médio e alto de $\mathrm{Zn}$ no solo correspondem a $<0,7 ; 0,7-1,5 \mathrm{e}>1,5 \mathrm{mg} \mathrm{dm}$ ${ }^{3}$, respectivamente. Portanto, espera-se que solos com concentração de $\mathrm{Zn}$ abaixo de $0,7 \mathrm{mg} \mathrm{dm}^{-3}$ apresentem alta probabilidade de resposta das plantas à aplicação do micronutriente.

\section{Efeito dos tratamentos na altura, área foliar e produção de matéria seca das mudas de goiabeira}

Houve efeito positivo e significativo das doses de zinco sobre a área foliar e a altura das mudas de goiabeira (Figura 3a). Pelo estudo das regressões, observou-se que a área foliar e a altura das plantas atingiram o máximo desenvolvimento com as doses de 1,8 e $2,5 \mathrm{mg} \mathrm{dm}^{-3}$ de Zn, respectivamente. Nas maiores doses de zinco, as plantas apresentaram decréscimo da área foliar e clorose geral com pigmentos pardo-avermelhados, sintomas estes descritos por Malavolta et al. (1997) como toxidez de zinco, em várias espécies. Além disso, nas maiores doses de $\mathrm{Zn}$, houve decréscimo considerável no volume do sistema radicular das mudas de goiabeira (Figura 2).

A matéria seca da parte aérea e das raízes das mudas de goiabeira aumentou, até certo ponto, com o incremento das doses de zinco (Figura 3b), em função do desenvolvimento das plantas em altura e em área foliar (Figura 3a). Efeitos positivos do Zn em doses moderadas foram observados, tanto no crescimento da parte aérea como do sistema radicular de algumas espécies, por Grunes et al. (1961), devido à conhecida função deste metal na síntese de auxina, que estimula o desenvolvimento e alongamento das partes jovens das plantas (Malavolta et al., 1997).

Da mesma forma que ocorreu com a área foliar e a altura das mudas, a maior produção de matéria seca da parte aérea e das raízes

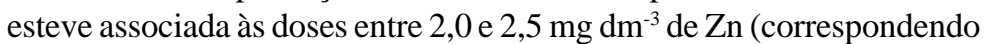
a 1,0-1,2 $\mathrm{mg} \mathrm{dm}^{-3}$ no substrato), bastante próximas daquelas observadas na Figura 3a.

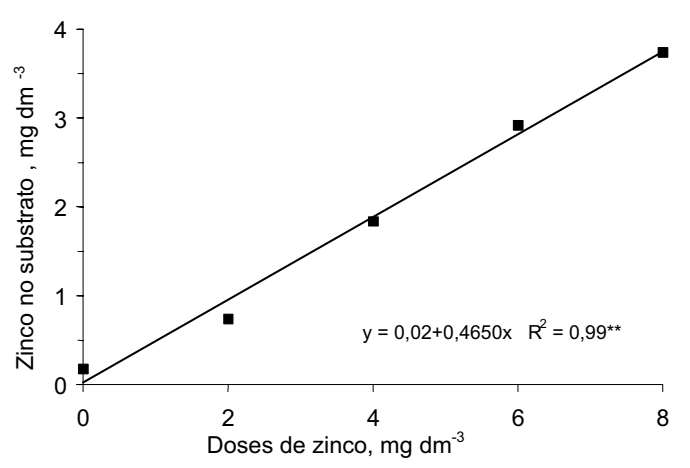

FIGURA 1 - Efeito de doses crescentes de zinco na concentração de Zn em substrato do Argissolo Vermelho-Amarelo (extrator DTPA). (Cada ponto é a média de cinco repetições).

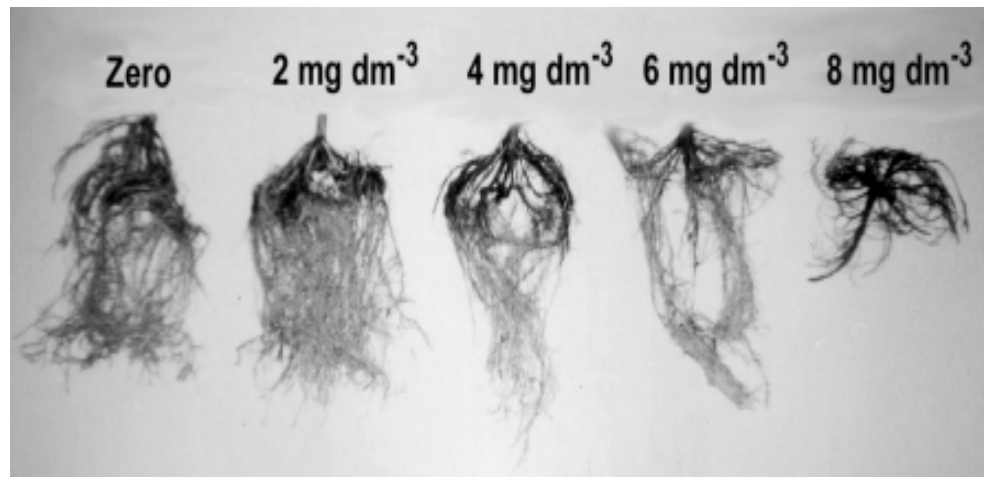

FIGURA 2 - Fotos do sistema radicular de mudas de goiabeira em função da aplicação de doses de zinco (zero, 2; 4; 6 e 8 $\mathrm{mg} \mathrm{dm}^{-3}$ ), após 135 dias do plantio. 


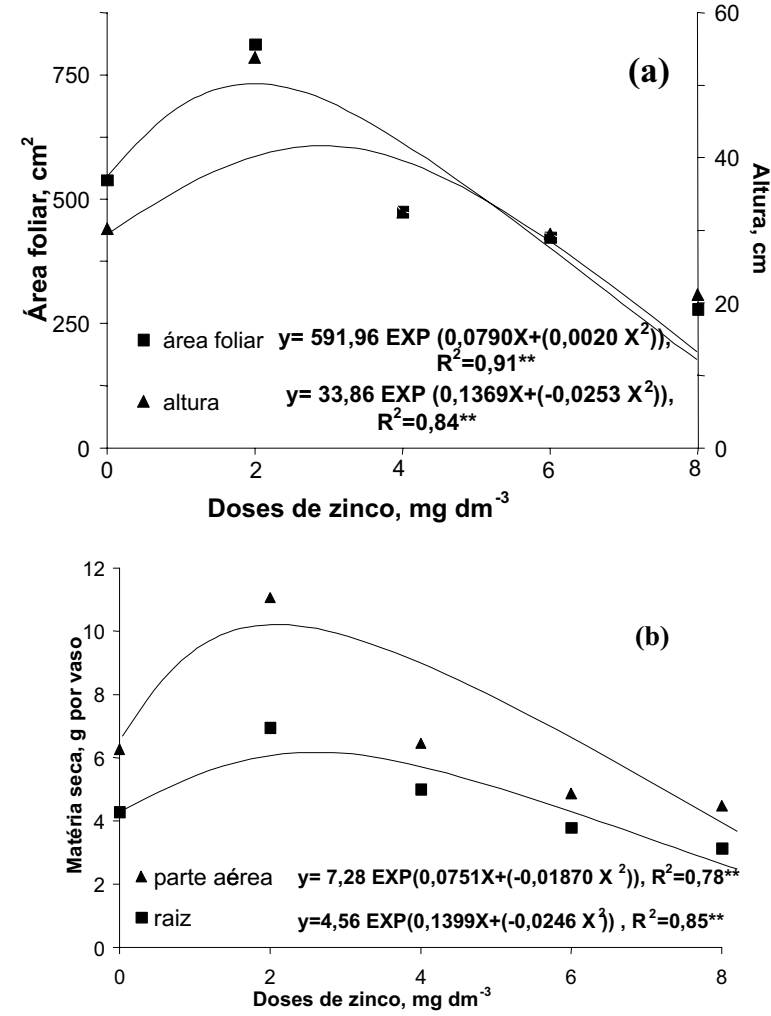

FIGURA 3 - Efeito da aplicação de zinco em substrato do Argissolo Vermelho-Amarelo na área foliar e na altura (a) e na produção de matéria seca da parte aérea e das raízes (b) das mudas de goiabeira, aos135 dias após o transplantio. (Cada ponto é a média de cinco repetições).

Tendo em vista a importância do sistema radicular para o estabelecimento das plantas, determinou-se a dose crítica de toxidez de $\mathrm{Zn}$ no solo que, para as mudas de goiabeira, foi de $3,0 \mathrm{mg} \mathrm{dm}^{-3}$. De acordo com Soares et al. (2001), esse valor reflete a dose de zinco aplicada ao solo que reduz em $10 \%$ a matéria seca das raízes. Portanto, doses de $\mathrm{Zn}$ acima da dose crítica de toxidez podem afetar o desenvolvimento radicular das mudas e, conseqüentemente, sua qualidade, podendo influenciar nas taxas de pegamento e homogeneidade do pomar a ser estabelecido.

Segundo Malavolta et al. (1997), a explicação para a redução na produção de matéria seca em plantas com toxidez de $\mathrm{Zn}$ é que, no xilema, acumulam-se tampões ("plugs") contendo o elemento, os quais dificultam a ascensão da seiva bruta.

Efeitos dos tratamentos no estado nutricional das mudas de goiabeira

Através dos resultados obtidos com a aplicação de zinco, observa-se que as características avaliadas foram depreciadas pelas maiores doses do metal. Assim sendo, buscou-se estabelecer relações entre o $\mathrm{Zn}$ aplicado no solo e a absorção e acúmulo de Zn e dos macronutrientes, com o intuito de levantar informações que fundamentem os efeitos da adubação na produção de mudas de goiabeira.

A absorção e acúmulo de zinco na matéria seca da parte aérea e das raízes aumentaram progressivamente com a elevação das doses de $\mathrm{Zn}$ aplicadas (Figura 4). Isto demonstra a habilidade das mudas de goiabeira na absorção do elemento do solo. Os teores de zinco considerados adequados em folhas de goiabeiras adultas situam-se entre 20-40 $\mathrm{mg} \mathrm{kg}^{-1}$ de Zn (Natale et al., 1996). No entanto, no presente estudo, os teores de $\mathrm{Zn}$ atingiram valores superiores na parte aérea das mudas ( $\mathrm{Fi}$ gura 4a), podendo estar em níveis tóxicos, o que poderia explicar o decréscimo na produção de matéria seca. Deve-se ressaltar, porém, que os tecidos vegetais amostrados e analisados são distintos, sendo o indicado por Natale et al. (1996) um par de folhas específico de árvores adultas, enquanto, no presente estudo, avaliou-se toda a parte aérea das mudas. Nota-se, ainda, que o Zn se concentra mais na parte aérea da planta, atingindo cerca de $69 \%$ do total. O mesmo fato foi observado por Salvador et al. (1999), relatando que $65 \%$ do total de $\mathrm{Zn}$ se concentrava na parte aérea.

O acúmulo de zinco na planta (parte aérea + raízes) descreveu um comportamento quadrático (Figura 4b), indicando que o excesso de Zn no solo provocou decréscimo no acúmulo do metal na planta. Este fenômeno é explicado pela redução linear do índice de translocação de $\mathrm{Zn}$, que foi de $75 \%$ na testemunha para $48 \%$ na dose máxima do elemento (Figura 5). Portanto, doses excessivas de $\mathrm{Zn}$ prejudicam mais os processos de translocação que os de absorção. De acordo com Vansteveninck et al. (1987), o fenômeno da redução de translocação do $\mathrm{Zn}$ pode ser explicado pelo mecanismo das plantas em aumentar a tolerância à toxidez de zinco, pois, nestas condições, tem-se maior acúmulo de $\mathrm{Zn}$ nos vacúolos das células do córtex da raiz.

Resultados semelhantes na queda do índice de translocação de Zn, com doses excessivas do metal, foram observados em mudas de outras plantas perenes, como eucalipto (Soares et al., 2001) e cafeeiro (Souza et al., 1999).
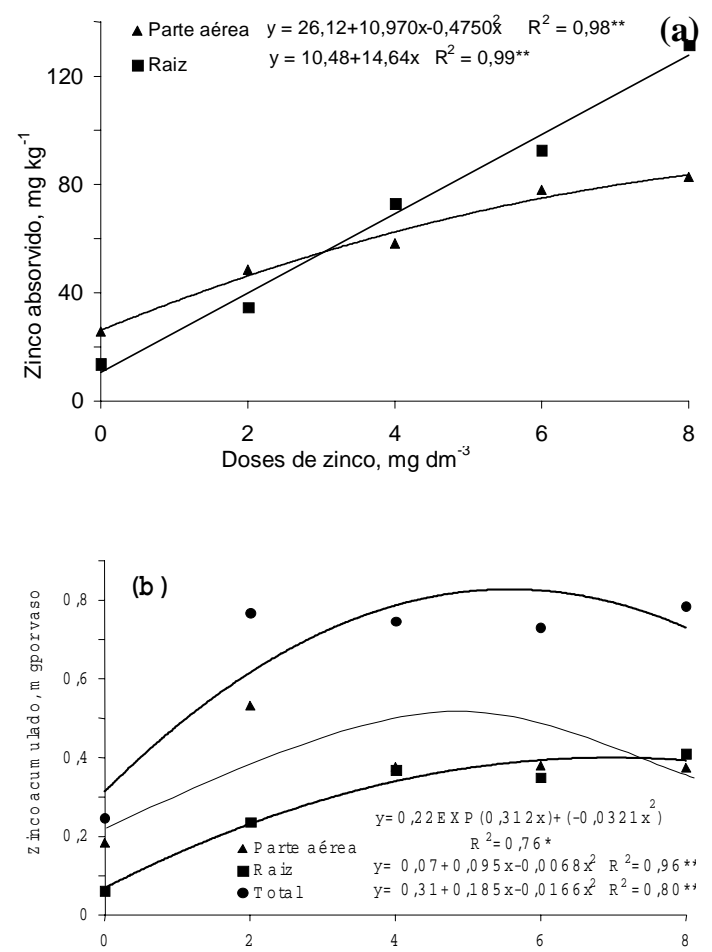

FIGURA 4 - Efeito da aplicação de zinco na absorção (a) e acúmulo (b) de $\mathrm{Zn}$ na parte aérea e nas raízes das mudas de goiabeira, cultivadas em substrato do Argissolo VermelhoAmarelo. (Cada ponto é a média de cinco repetições).

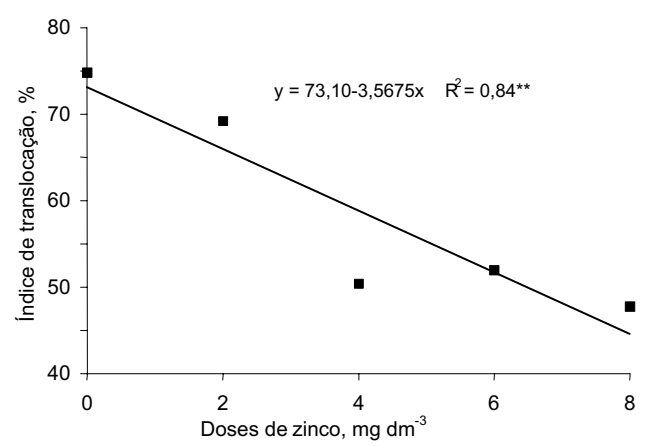

FIGURA 5 - Efeito da aplicação de zinco no índice de translocação de $\mathrm{Zn}$, em mudas de goiabeira cultivadas em substrato do Argissolo Vermelho-Amarelo. (Cada ponto é a média de cinco repetições). 
O acúmulo de macronutrientes na parte aérea e nas raízes das mudas de goiabeira foi significativamente influenciado pelas doses de zinco aplicado, exceto o N na parte aérea (Figura 6). Observa-se, inicialmente, um acréscimo e, depois, uma redução no acúmulo dos macronutrientes nas plantas, em função do incremento nas doses de $\mathrm{Zn}$ aplicadas ao solo, à semelhança do ocorrido com a produção de matéria seca. Nota-se que as raízes são mais tolerantes às doses de $\mathrm{Zn}$, uma vez que, na parte aérea, doses superiores a 1,2-1,8 $\mathrm{mg} \mathrm{dm}^{-3} \mathrm{de} \mathrm{Zn}$ causaram decréscimo no acúmulo dos macronutrientes, ao passo que, nas raízes, estas doses corresponderam a 2,4-3,4 $\mathrm{mg} \mathrm{dm}^{-3}$ de $\mathrm{Zn}$. Entre os macronutrientes, o Ca e o $\mathrm{P}$ foram mais sensíveis à aplicação de zinco, pois doses maiores que 1,2 e $1,4 \mathrm{mg} \mathrm{dm}^{-3}$ de $\mathrm{Zn}$, respectivamente, já foram suficientes para causar redução no acúmulo desses elementos na parte aérea das mudas. Na literatura, tem sido relatado que o excesso de Zn pode diminuir a absorção de $\mathrm{P}$ (Malavolta et al.,1997) e de Ca (Brown et al., 1995) pelas plantas.
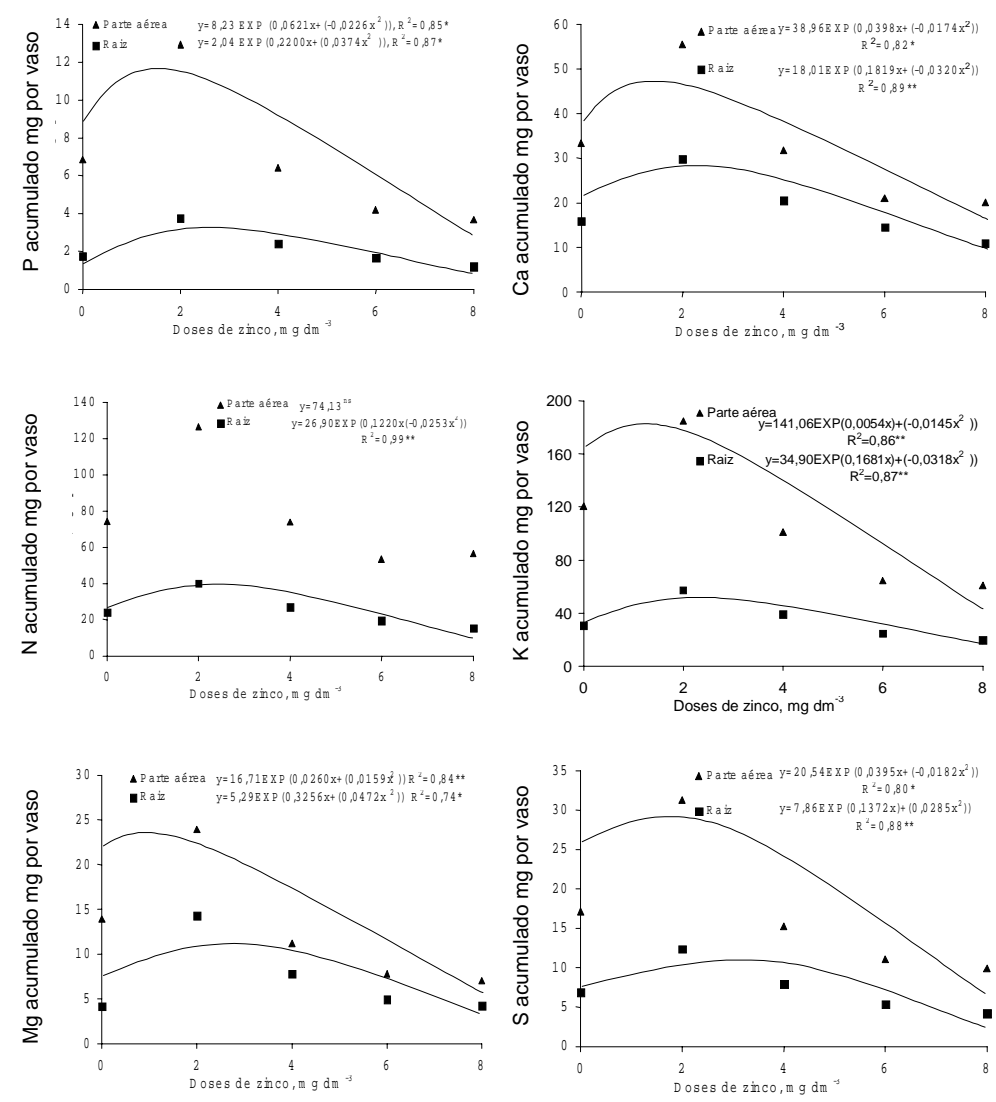

FIGURA 6 - Efeito da aplicação de zinco em substrato do Argissolo Vermelho-Amarelo, sobre o acúmulo de macronutrientes na parte aérea e nas raízes de mudas de goiabeira, aos 135 dias após o transplantio. (Cada ponto é a média de cinco repetições).

\section{CONCLUSÕES}

1) As mudas de goiabeira responderam à aplicação de zinco em substrato com baixo teor de $\mathrm{Zn}$.

2) O maior desenvolvimento das plantas esteve associado à dose próxima de $2 \mathrm{mg} \mathrm{dm}^{-3}$ de $\mathrm{Zn}$, o que corresponde a cerca de $1 \mathrm{mg} \mathrm{dm}^{-3}$ de $\mathrm{Zn}$ no solo (extrator DTPA).

3) Doses iguais ou superiores a $4 \mathrm{mg} \mathrm{dm}^{-3} \mathrm{de} \mathrm{Zn}$ (cerca de $2 \mathrm{mg} \mathrm{dm}^{-3} \mathrm{de}$ $\mathrm{Zn}$ no solo) provocaram redução significativa no desenvolvimento e acúmulo de macronutrientes nas mudas de goiabeira.

\section{REFERÊNCIAS BIBLIOGRÁFICAS}

BARMAN, K.K.; GANESHAMURTHY, A.N.; TAKKAR, P.N. Zinc requeriment of soybean (Glycine max) - wheat (Triticum aestivum) cropping sequence in some swell-shrink soils. Indian Journal of Agricultural Sciences, New Delhi, v.68, n.12, p.759-761, 1998.
BATAGLIA, O.C.; FURLANI, A.M.C.; TEIXEIRA, J.P.F.; FURLANI, P.R.; GALLO, J.R. Métodos de análise química de plantas. Campinas: Instituto Agronômico, 1983. 48p. (Boletim Técnico, 78). BRASIL. Ministério da Agricultura. Portaria no 40 de 20/05/1977

BROWN, S.L.; CHANEY, R.L; ANGLE, J.S.; BAKER, A.J.M. Zinc and cadmium uptake by hyperaccumulator Thlaspi caerulescens grown in nutrient solution. Soil Science of American Journal, Madi son, v.59, p.125-133, 1995.

FACHINELO, J.C.; NACHTIGAL, J.C.; KERSTEN, E. Fruticultura: fundamentos e práticas. Pelotas: Editora Universidade Federal de Pelotas, 1996. 311p.

FAO. Production. Roma. Disponível em: <http://apps.fao.org> Acesso em: 10 nov. 1998.

GRUNES, D.L.; BOAWN, L.C.; CARLSON, C.W.; VIETS JR., F.G. Zinc deficieny of corn and potatoes, as related to soil and plant analysis. Agronomy Journal, Madison, v.53, p.68-71, 1961.

KABATA-PENDIAS, A.; PENDIAS, H. Trace elements in soils and plants. Boca Raton: CRC, 1985. 315p.

KANEGAE, F.P. Efeitos da calagem e da adubação fosfatada na produção de mudas de goiabeira. 1998. 45f. Monografia (Trabalho de Graduação em Agronomia) - Faculdade de Ciências Agrárias e Veterinárias, Universidade Estadual Paulista, Jaboticabal, 1998.

MALAVOLTA, E. Manual de química agrícola: adubos e adubação. 3.ed. São Paulo: Agronômica Ceres, 1981. 594p.

MALAVOLTA, E.; VITTI, G.C.; OLIVEIRA, S.A. Avaliação do estado nutricional das plantas: princípios e aplicações. Piracicaba: POTAFÓS, 1997. 319p.

MARSCHNER, H. Mineral nutrition of higher plants. 2.ed. San Diego: Academic, 1995. 902p.

NATALE, W.; COUTINHO, E.L.M.; BOARETTO, A.E.; PEREIRA, F.M. Goiabeira: calagem e adubação. Jaboticabal: FUNEP, 1996. 22p.

PRASAD, N.; MATHUR, R.L.; CHATTRI, I.S. Studies on the control of zinc deficiency of guava in Rajasthan. Indian Journal Agricultural Sciences, New Delhi, v.36, n.4, p.201-209, 1966.

RAIJ, B.van, CANTARELLA, H., QUAGGIO, J.A, FURLANI, A.M.C. (Eds.) Recomendações de adubação e calagem para o Estado de São Paulo.2.ed. Campinas: Instituto Agronômico \& Fundação IAC, 1996. p.39. (Boletim Técnico, 100).

RAIJ, B.van.; ANDRADE, J.C.; CANTARELLA, H.; QUAGGIO, J.A. (Eds.) Análise química para avaliação da fertilidade do solo. Campinas: Instituto Agronômico, 2001. 285p.

SALVADOR, J.O.; MOREIRA, A.; MURAOKA, T. Efeito da omissão combinada de N, P, Ke S nos teores foliares de macronutrientes em mudas de goiabeira. Scientia Agricola, Piracicaba, v.56, p.501-507, 1999.

SANTOS, R.R.; QUAGGIO, J.A. Goiaba. In: RAIJ, B.van; CANTARELLA, H.; QUAGGIO, J.A.; FURLANI, A.M.C. (Ed.) Recomendações de adubação e calagem para o Estado de São Paulo. Campinas: Instituto Agronômico, 1996. p.143. (Boletim Técnico, 100).

SOARES, C.R.F.S.; GRAZZIOTTI, P.H.; SIQUEIRA, J.O.; CARVALHO, J.G.; MOREIRA, F.M.S. Toxidez de zinco no crescimento e nutrição de Eucalyptus maculata e Eucalyptus urophylla em solução nutritiva. Pesquisa Agropecuária Brasileira, Brasília, v.36, n.2, p.339-348, 2001.

SOUZA, C.A.S.; GUIMARÃES, P.T.G.; FURTINI NETO, A.E.; NOQUEIRA, F.D. Resposta de três cultivares de cafeeiro (Coffea arabica L.) ao zinco aplicado via solo. In: CONGRESSSO BRASILEIRO DE CIÊNCIA DO SOLO, 27., Brasília,1999. Resumos: Brasília: Universidade de Brasília/EMBRAPA Cerrados/SBCS, 1999. (CD Rom).

VANSTEVENINCK, R.F.M.; VANSTEVENINCK, M.E.; FERNANDO, D.R.; GODBOLD, D.L.; HORST, W.J.; MARSCHNER, H. Identification of zinc-containing glogules in roots of a zinc-tolerant ecotype of Deschampsia caespitosa. Journal of Plant Nutrition, Monticello, v.10, p.1239-1246, 1987.

VASUDEVA, R.S.; RAYCHAUDHURI, S.P. Guava disease in Pushkar Valley and its control. Indian Phytopathogy, New Delhi, v.7, p.78-81, 1954. 